This item was submitted to Loughborough's Research Repository by the author.

Items in Figshare are protected by copyright, with all rights reserved, unless otherwise indicated.

\title{
Experimental and numerical evaluation of influencing parameters on the manufacturing of lined pipes
}

\section{PLEASE CITE THE PUBLISHED VERSION}

https://doi.org/10.1016/j.ijpvp.2018.11.014

PUBLISHER

Crown copyright @ Elsevier

VERSION

AM (Accepted Manuscript)

\section{PUBLISHER STATEMENT}

This paper was accepted for publication in the journal International Journal of Pressure Vessels and Piping and the definitive published version is available at https://doi.org/10.1016/j.ijpvp.2018.11.014.

LICENCE

CC BY-NC-ND 4.0

\section{REPOSITORY RECORD}

Kalaki, Ali, Mehdi Eskandarzade, Saeed Barghani, and Mahdi Mohammadpour. 2019. "Experimental and Numerical Evaluation of Influencing Parameters on the Manufacturing of Lined Pipes". figshare.

https://hdl.handle.net/2134/36195. 


\title{
Experimental and Numerical Evaluation of Influencing Parameters on the Manufacturing of Lined Pipes
}

\author{
Ali Kalaki ${ }^{1}$, Mehdi Eskandarzade ${ }^{2 *}$, Saeed Barghani ${ }^{3}$, M. Mohammadpour ${ }^{4}$ \\ 1. Technical and Corrosion Protection Department, Iranian Central Oil Fields Co., Tehran, Iran. \\ 2. Mechanical Engineering Group, Faculty of Engineering, University of Mohaghegh Ardabili, \\ Ardabil, Iran. \\ 3. Manufacturing Department, AzarAb Industries Co., Arak, Iran. \\ 4. Wolfson School of Mechanical, Electrical and Manufacturing Engineering, \\ Loughborough University, Loughborough, UK \\ *m.eskandarzade@uma.ac.ir
}

\begin{abstract}
The amount of residual contact stress between an inner corrosion-resistant alloy pipe and its external carbon steel counterpart is the main challenge when manufacturing lined pipes. This study outlines the experimental and numerical evaluation of the manufacturing parameters of mechanically bonded double-walled pipes, produced by the thermo hydraulic shrink fit process. The measurements indicate that the gripping force between the outer 4-inch carbon steel and inner 3-inch stainless steel pipes was $33.94 \mathrm{MPa}$ when processed at $350^{\circ} \mathrm{C}$ with a hydraulic pressure of $30 \mathrm{MPa}$. The experimental results correlate with those of finite element method simulations for gripping force. The magnitudes of the measured gripping forces in the experiment are sufficiently high for most scenarios. The cross-sections of the final lined pipes were inspected for possible defects with the most common being the lamination-type defect for this production process.
\end{abstract}

Key words: Corrosion-resistant alloys, Piping, Oil and gas industry, Thermo hydraulic shrink fit process, Gripping force.

\section{Nomenclature:}

$\begin{array}{cl}F_{L, g r i p p i n g} & \text { gripping force } \\ \tau_{c} & \text { interfacial shear resistance between two pipes } \\ A_{L} & \text { area of dislodgment region on inner pipe external surface } \\ \sigma_{c} & \text { interfacial residual stress after shrinking of outer pipe } \\ \mu & \text { friction coefficient at interface } \\ r_{o i} & \text { outer radius of inner pipe } \\ r_{i i} & \text { inner radius of inner pipe } \\ R_{i o} & \text { inner radius of outer pipe }\end{array}$




$\begin{array}{ll}R_{\text {oo }} & \begin{array}{l}\text { outer radius of outer pipe } \\ \sigma_{y l}^{\prime}\end{array} \\ \begin{array}{c}\text { equivalent yield stress (after considering plastic hardening } \\ \text { stress) of inner pipe }\end{array} \\ \sigma_{y i} & \text { yield strength of inner pipe } \\ P_{h} & \text { hydraulic load pressure } \\ v_{l} & \text { Poisson's ratio of inner pipe } \\ v_{o} & \text { Poisson's ratio of outer pipe } \\ E_{l} & \text { Young's modulus of inner pipe } \\ E_{o} & \text { Young's modulus of outer pipe } \\ D_{i} & \text { inner diameter of outer pipe } \\ D_{o} & \text { outer diameter of outer pipe } \\ t & \text { thickness of inner pipe }\end{array}$

\section{Introduction}

Corrosion-resistant alloys (CRAs) are being increasingly applied for different industrial applications, an example of which is the upstream oil and gas industry [1]. Exploiting industries have increased the amount of oil and gas extracted from deeper wells, because the production pressure increases with increased reservoir depth [2]. Moreover, with the current offshore oil and gas extraction technology, untreated hydrocarbon products are being transported over longer distances from subsea wells to processing facilities. All of these factors necessitate special attention to the use of corrosion-resistant materials to mitigate $\mathrm{CO}_{2}$ and/or $\mathrm{H}_{2} \mathrm{~S}$ attacks [3]. The deployment of corrosion management systems has increased the focus on reducing maintenance costs, as well as increasing the life of piping and pipeline systems by utilising appropriate material selection methods [4]. The main problem associated with CRAs is that they do not provide sufficient strength to resist the required working pressure. Hence, they are used as a thin internal coat inside cheaper non-CRA pipes in highpressure applications. Metallurgically bonded double-walled pipes, known as clad pipes, and mechanically bonded double-walled pipes, known as lined pipes, are two main categories of CRA pipes [5]. In addition to the advantages offered in terms of corrosion, lined pipes exhibit improved mechanical strength owing to the residual stress between the inner and outer pipes. This residual stress also determines the amount of gripping force at the interface of the two pipes, which has been studied by numerous researchers. However, no experimental data are available to validate the numerical and analytical studies. The required specifications of double-walled CRA pipes with applications in the oil, gas and petrochemical industry are presented in API SPEC 5LD [6]. Lined pipes are superior to clad pipes in various applications because of their lower production costs and availability in all sizes. Generally, in lined pipes, the corrosion-resistant inner pipe is mechanically bonded to the outer carbon steel pipe. The binding stage can be carried out using high hydraulic pressure, with or without 
applying heat on the inner pipe. If the outer pipe is heated prior to the hydraulic binding stage, the process is referred to as thermo hydraulic shrink fit (THSF). The hydro-expanding principle of the forming in the production of lined pipes has been discussed in literature [7]. Moreover, simplified expressions for predicting the hydro-forming pressure and residual stress while forming double-walled pipes have been presented by Zheng et al. [8].

Furthermore, the performance of mechanically lined pipes was studied by Mizumura et al. under the following loading conditions: (1) interfacial gas pressure between the inner and outer pipes; (2) bending load; (3) tensile load; and (4) internal pressure [9]. The occurrence of wrinkling is an important challenge in producing lined pipes [10]. This phenomenon mostly occurs as a result of unwanted axial forces during the fitting or pressurising stages $[11,12]$. However, the residual stress between the inner and outer pipe is a key quality criterion of lined pipes. This issue was researched by Guo et al. [13] using theoretical methods. The authors considered the inner and outer pipes as thin and thick-walled cylinders, respectively; however, heat was not included in their research. The force distribution of the lined pipes during or after manufacturing has been studied by numerous researchers by means of analytical methods $[11,14]$. Moreover, several finite element studies have been conducted regarding the production of lined pipes $[15,16]$.

As discussed above, in the manufacturing of lined pipes, the residual stress between the inner and outer pipes is the most important parameter. The value of the residual stress in mechanically bonded double-walled pipes is influenced by various parameters, such as the liner pipe yield stress, strain hardening, and thermal expansion coefficient [17].

A three-dimensional (3D) finite element analysis of the THSF process has been performed in the current study. The amounts of gripping force, residual stress, and strain at the inner and outer pipes were obtained during the pressurising stages. The results were confirmed with experimental measurements wherever applicable.
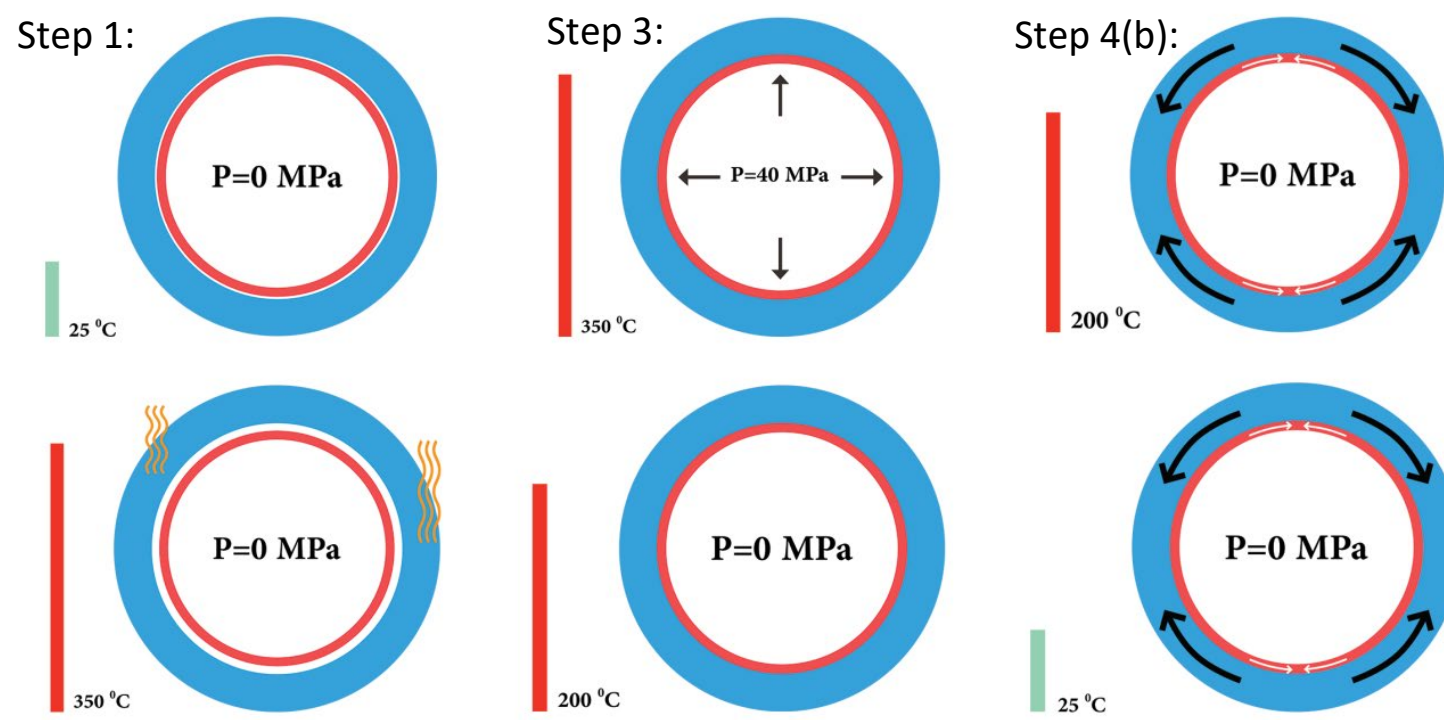

Step 2:

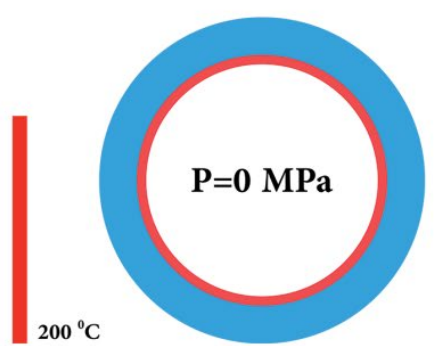

Step 4(a):

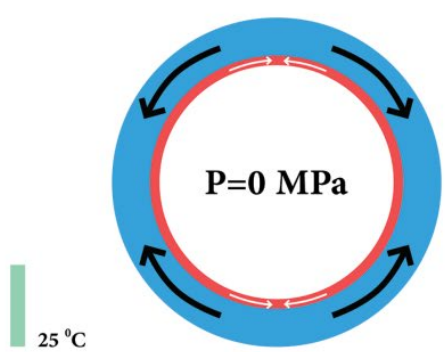

Step 5:

Figure 1: Schematic of THSF process 


\section{Principle of THSF Process}

Figure 1 presents a schematic of the THSF process. As illustrated in the figure, THSF consists of several steps as follows.

Step 1: Beginning of the process. The required inspections and pre-process tests are conducted, and the pipes are ready to be manufactured through THSF.

Step 2: Heating of outer pipe. The outer pipe is heated through temperature exposure, which does not change the pipe microstructure. The aim of heating the outer pipe is to increase its diameter by thermal expansion to locate the inner pipe easily, as well as to provide sufficient clearance for plastic deformation of the inner pipe in the following stages. If the clearance for the pipe lengths and diameters is not designed effectively, the task of fitting two pipes will be challenging. In particular, when the pipes have been heated, their displacement occurs with relative difficulty.

Step 3: Application of hydraulic pressure to inner pipe until bonded to internal surface of outer pipe. During this stage, internal hydraulic pressure is applied to the thin inner pipe until yielding. Then, it expands until it comes in contact with the internal surface of the outer thick carbon steel pipe. The pressure increases until the surfaces of the two pipes are completely stuck together, but the maximum pressure always remains below the stress range, which exceeds the yield stress of the outer pipe.

Step 4: Relief of internal pressure: After several minutes, the pressure is removed; consequently, the diameters of both pipes are reduced owing to the reverse elastic strains. Considering the fact that the thermal expansion ratios for carbon and stainless steel differ, two scenarios based on the amount of initial clearance between the diameters of the inner and outer pipes may occur. The first possible scenario is that the two pipes disconnect from one another following pressure relief and there is no residual stress in this condition (Step 4(a)). The second possible scenario is that the two connected surfaces remain connected; then, residual stress will exist between the two surfaces following pressure relief (Step 4(b)). The second scenario is most common in THSF pipes.

Step 5: Complete cooling of inner and outer pipes (outer pipe shrinks around inner pipe). The outer pipe begins to cool down and consequently shrinks and hoops the inner pipe. In the equilibrium state, the outer pipe is exposed to the residual tensile stress, while the inner pipe is exposed to compressional stress.

Although the fundamentals of manufacturing lined pipes are very simple, there are always numerous challenges and difficulties in the application of the process. Some of the most critical problems in manufacturing THSF pipes are as follows.

- Several parts of the process should be conducted in high-temperature conditions. High temperatures may cause oxidation of the connecting surfaces, which is undesirable.

- A safety issue exists when processing at internal pressures of 30 to $40 \mathrm{MPa}$. 
- In general, pipes exhibit variations regarding their wall thickness. Hence, certain thick/thin regions in one or both pipes require extra pressure to deform and these regions will be the locations of misconnected areas without additional pressure consideration.

- Full ultrasonic testing is necessary to ensure that no lamination-type defects exist on the connecting surfaces of the pipes. These lamination-type defects may be the locations of hydrogen-induced defects.

\section{Gripping Force}

The required force for pushing out the inner pipe can be calculated by Eqs. (1) to (3).

$$
\begin{gathered}
F_{L, \text { gripping }}=\tau_{c} \times A_{L} \\
\tau_{c}=\sigma_{c} \cdot \mu \\
A_{L}=2 \pi r_{o i} \cdot L
\end{gathered}
$$

It is evident from the above equations that the gripping force is directly related to the residual stress at the interface, which itself depends on the initial gap at the interface, liner pipe yield stress, and magnitude of the hydraulically applied pressure. Numerous researchers have attempted to estimate the residual stress between two pipes. The inner pipe is commonly assumed as a thin-walled cylinder and the related equations can be used. However, in general, the outer carbon steel pipe has an outside radius-to-thickness ratio of less than 20 and a thick cylinder formula should be used for this section of the lined pipe. According to Guo et al. [13], without considering the temperature effect, the residual stress value can be estimated using the following analytical equations.

$$
\begin{gathered}
A \sigma_{c}=B P_{h}-2 \sigma_{y l}^{\prime}\left(B \frac{t}{D_{i}}+\frac{1}{\sqrt{3} E_{l}}\right) \\
A=\frac{1}{E_{l}}\left(\frac{D_{i}}{2 t}-v_{l}\right)+\frac{1}{E_{0}}\left(\frac{D_{0}^{2}+D_{i}^{2}}{D_{0}^{2}-D_{i}^{2}}+v_{0}\right) \\
B=\frac{1}{E_{l}}\left(1-v_{l}\right)+\frac{1}{E_{0}}\left(\frac{D_{0}^{2}+D_{i}^{2}}{D_{0}^{2}-D_{i}^{2}}+v_{0}\right)
\end{gathered}
$$

\section{Materials and Method}

\subsection{Finite element modelling}

A 3D finite element model (FEM) simulation of the THSF process was performed in this study. In the THSF process, thermal and displacement stresses exhibit interactions that are necessary for conducting the coupled displacement-temperature analysis. In this type of 
analysis, the nodes have temperature, rotation, and displacement degrees of freedom, implying a significantly lengthy analysis time. To reduce the analysis time, it is possible to utilise two uncoupled analyses for the thermal and displacement fields. To achieve this, firstly, thermal analysis should be performed, followed by a displacement analysis, which utilises the temperature distribution results from the previous analysis. However, in this study, to achieve the highest accuracy, a coupled displacement-temperature analysis was conducted. The analysis was performed using Dynamic/Explicit Abacus software.

The contact problem is very complex in THSF, as the contact region changes rapidly during the process. The Coulomb friction model was used to simulate the contact between the inner and outer pipes. For this contact pair, the internal surface of the outer pipe was assumed as the master surface, while the external surface of the inner pipe was assumed as the slave surface. The required material properties, such as conductivity and specific heat, were defined as a function of temperature. To achieve strong agreement between the results and experimental measurements, the part dimensions were assigned based on Table 1 (as per the experiment). The materials of the liner and outer pipe were considered as elastic-plastic, described through the ASTM standard and as per the experiment.

In the loading module, the first step was to heat the outer pipe to $350^{\circ} \mathrm{C}$. In the following step, hydraulic pressure of approximately $30 \mathrm{MPa}$ was applied to the internal surface of the inner pipe. Eight-node reduced-integration elements (C3D8R) were employed for the modelling of the pipes. Owing to the reduced integration characteristic of this element type, not only was the locking phenomenon eliminated, but the computational time was also reduced considerably. The latter was vital in modelling the THSF process. Regarding the precision, this element was preferred to the fully integrated element (C3D8) in terms of plasticity and problems involving high strains. The integration point of the C3D8R element was located in the middle of the element; the stress and strain values were, thus, most accurate at the integration points. Hourglassing was the main issue when using this element, which would not affect the results. In this study, hourglass control was set to the enhanced mode.

Table 1: Variation in thickness and diameter of inner and outer pipes

\begin{tabular}{cccc}
\hline & $\begin{array}{c}\text { Outside diameter } \\
\text { range }(\mathrm{mm})\end{array}$ & $\begin{array}{c}\text { Inside diameter } \\
\text { range } \\
(\mathrm{mm})\end{array}$ & $\begin{array}{c}\text { Thickness range } \\
\text { (mm) }\end{array}$ \\
\hline Inner pipe & 85.6 to 85.8 & 80.15 to 80.40 & 5.40 to 5.50 \\
Outer pipe & 114.2 to 114.5 & 87.1 to 87.5 & 13.5 to 13.7 \\
\hline
\end{tabular}

\subsection{Experiments}

A stainless CRA inner tube with specifications of ASTM A213 TP316L — seamless, nominal 3 -inch diameter, and schedule of 40 - a carbon steel outer pipe with specifications of API 5L X52 - seamless, PSL2, nominal 4-inch diameter, and 13.5-mm thickness-and NACE MR0175 were used. The TP316L grade stainless tube is the standard molybdenum bearing grade and exhibits superior overall corrosion-resistant properties compared with 304 grades. In particular, it offers higher resistance against pitting and crevice corrosion in chloride 
environments. The minimum yield strength of the TP316L grade is approximately $170 \mathrm{MPa}$ and average coefficient of thermal expansion of the material is approximately $15.9,1 /{ }^{\circ} \mathrm{C}$. It also exhibits excellent welding characteristics and post-weld annealing is generally not required; the low carbon content eliminates carbon precipitation in the welding process. It is an excellent option for severely corrosive environments. It was economical to use TP316L grade to benefit from its corrosion resistance and to use X52 grade as the outer layer to benefit from its mechanical resistance. The X52 material grade has a minimum yield strength of $300 \mathrm{MPa}$ and mean linear thermal expansion of $14.3,1 /{ }^{\circ} \mathrm{C}$. It is one of the most common standard line pipe materials in the oil and gas industry. In the experiments of the current study, the lengths of both pipes were $4000 \mathrm{~mm}$. The changes in the thickness and diameter of the pipes were measured and are presented in Table 1. According to these measurements, there was an initial gap of 1.3 to 1.9 between the inside and outside diameters of the inner and outer pipes. Prior to starting the main processing steps, the two ends of the inner pipe were blocked using special caps. However, two inlets were embedded in one of the caps to fill/unfill the inner pipe with water and to install the digital pressure gauge. During the first step, the temperature of the outer carbon steel pipe was increased to $350^{\circ} \mathrm{C}$ using standard induction coils. The specification of the coils satisfies the Iranian National Standard (IPS-MIN-120). Thereafter, the inner pipe with a 3-inch nominal diameter was assembled in the outer pipe with a 4-inch nominal diameter. Figure 2 (left) displays the experimental setup of the current study.
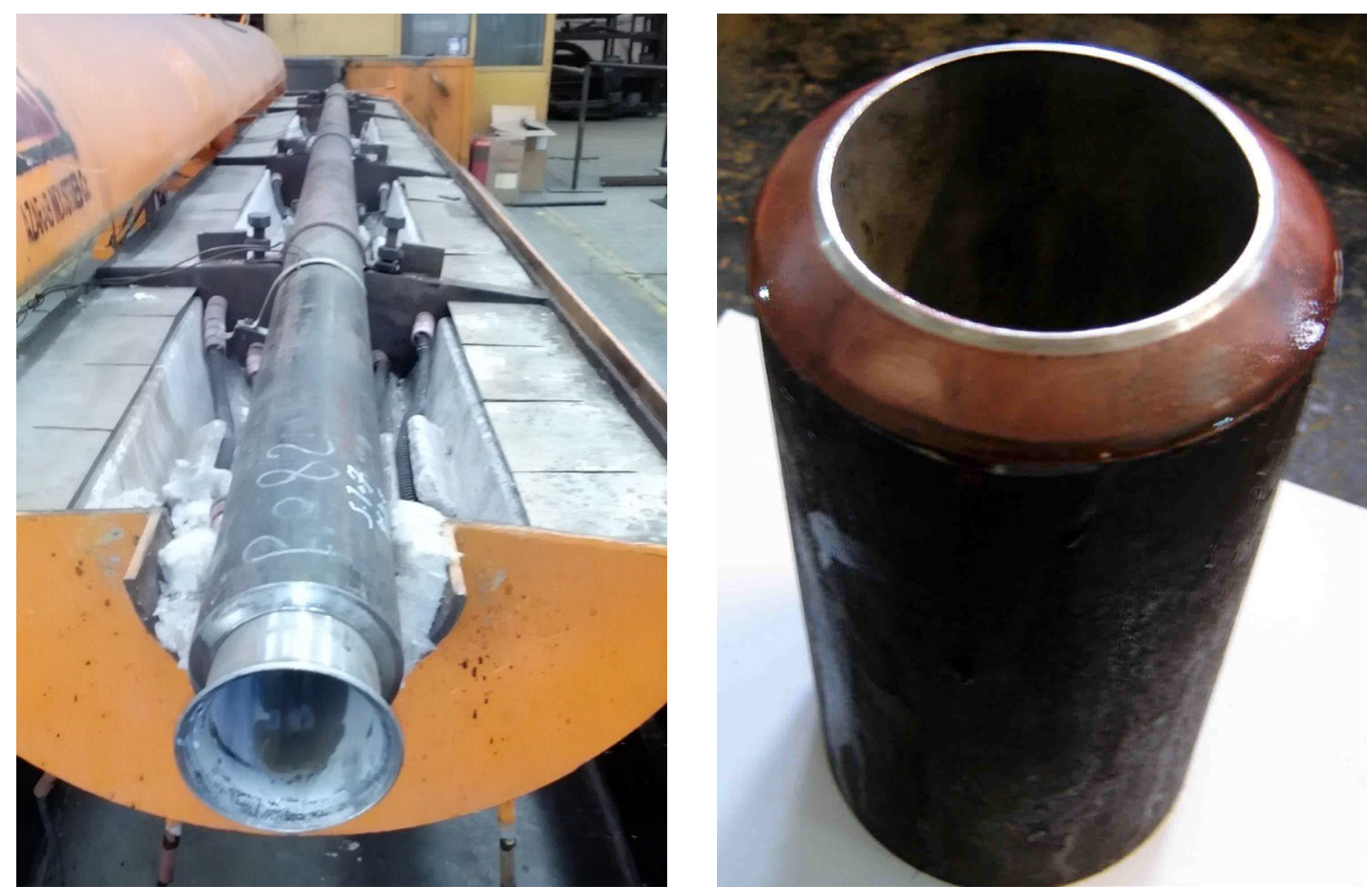

Figure 2: Experimental setup of THSF process (left); lined pipe produced for this study (right) 

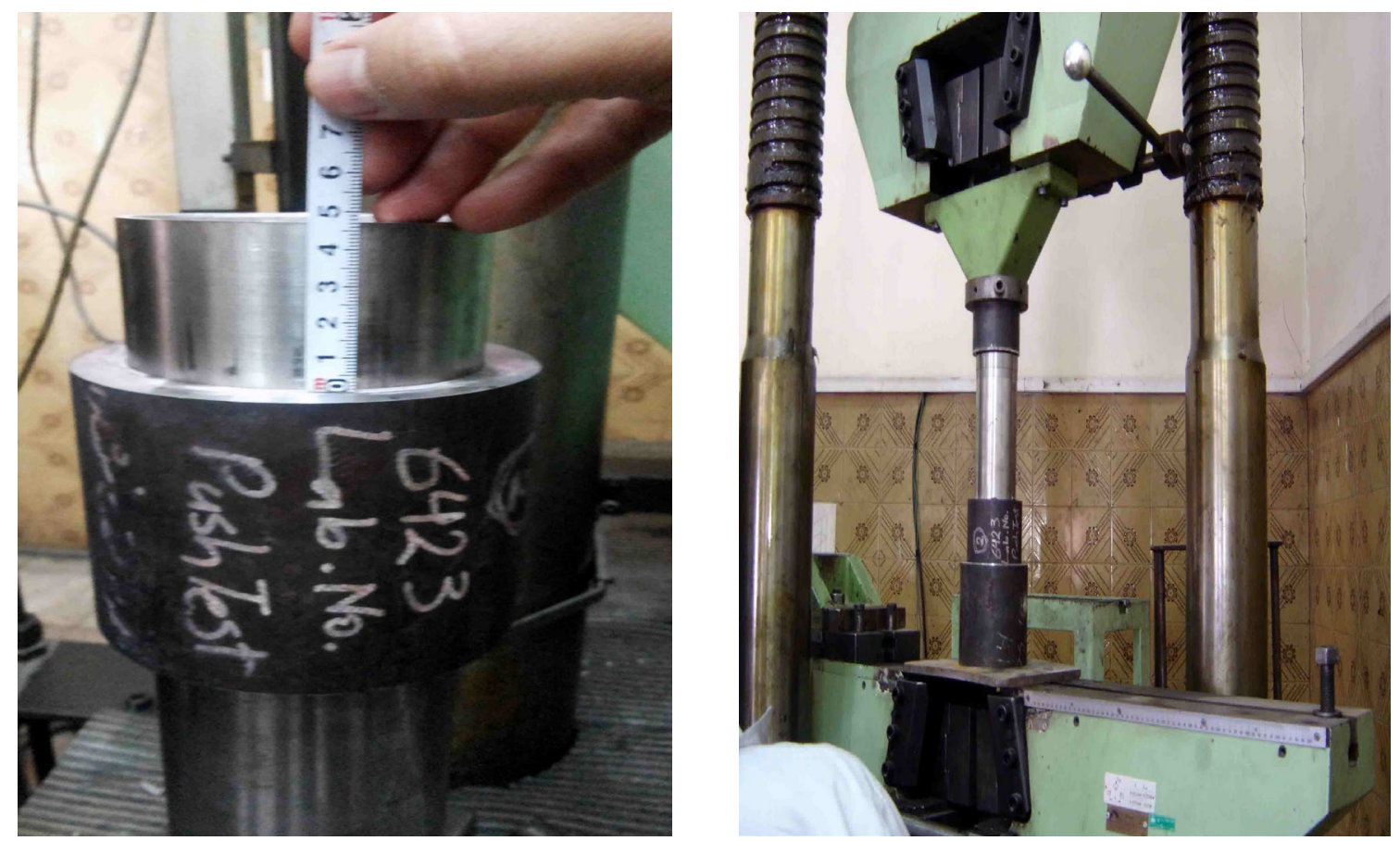

Figure 3: Experimental setup for push-out test (left); sample after pushing out inner pipe (right)

Thereafter, the inside pressure of the inner pipe was increased to $30 \mathrm{MPa}$ and was allowed to remain at this pressure for $5 \mathrm{~min}$. After this time, the pressure was relieved to atmospheric pressure. Figure 2 (right) illustrates the final double-walled pipe that was produced in this study. Finally, a push-out test was conducted to measure the amount of gripping force in the mechanically bonded interface of the pipes. Figure 3 presents the experimental setup for the push-out test of the present study.

\section{Results and Discussion}

\subsection{Simulation}

In this study, 3D FEM analysis was conducted to estimate the residual stress at the interface of the two pipes. Figure 4 illustrates the model of the current study. The results of the FEM analysis for the stress/strain changes during the heating and pressurising stages of the THSF process are presented in Fig. 5. According to the figure, the radius of the 3 -inch pipe increased elastically by $0.05 \mathrm{~mm}$ when increasing the internal pressure at a hoop stress of 250 MPa (point 1 in Fig. 5). Thereafter, the pipe material experienced plastic deformation; consequently, the 3 -inch pipe radius increased to $43.86 \mathrm{~mm}$ by further increasing the internal pressure (point 2, Fig. 5), where it contacted the internal surface of the 4-inch pipe. At this point, the outer pipe had expanded thermally to a radius of $43.8 \mathrm{~mm}$ owing to the initial heating, and the two pipes contacted one another. Thereafter, the internal pressure of the inner pipe dropped and the radius of both pipes decreased. As a result of the pressure relief, the displacement stresses in the 3 -inch pipe were reduced to 0 at a radius of $43.84 \mathrm{~mm}$ (point 
3, Fig. 5). Again, the two pipes had approximately the same radius. In the following steps, and by gradually decreasing the temperature of the pipes to room temperature, the outer pipe tended to shrink more than the inner pipe, but the inner pipe restrained the outer pipe shrinkage. As a result, the 3-inch inner pipe was exposed to compression stress (point 4, Fig. 5) and the 4-inch outer pipe was exposed to tensile stress (point 4, Fig. 5). The red solid drawn curve in Fig. 5 indicates the behaviour of the 4-inch (carbon steel) pipe. The pipe radius increased continuously, without any change in the stress value, from 43.65 to 43.84 $\mathrm{mm}$ owing to the initial heating. The magnitude of the tensile stress in the outer pipe at point 4 (Fig. 5) was equal to the amount of compression stress in the inner pipe at point 4 (Fig. 5). This value was $190 \mathrm{MPa}$, known as the residual stress between two pipes. A rapid drop occurred from 190 to $125 \mathrm{MPa}$ in the curve related to the 4-inch pipe. At this point, a break occurred at the outer pipe, which would not be the case in practice. The strain-hardening phenomenon was not considered in the simulation of the present study, resulting in the occurrence of this discrepancy.

The important aspect in the pressurising stage of the lined pipes is that pressure values above the elastic strength of the outer pipe should be avoided. This is owing to the fact that the pressure calculation formulae in most pipeline and piping codes, such as ASME B31.8 and B31.3, are based on the elastic deformation in pipes. Hence, in the present study, this problem was evaluated before pressurising the inner pipe, as illustrated in Fig. 6. In the analysis of this section, the pressure increased up to $50 \mathrm{MPa}$ and it is clear that the equivalent hoop stress in the outer pipe was $225 \mathrm{MPa}$, which is substantially lower than the yield strength of the X52 carbon steel pipe. The yield strength of the X52 pipe was $358 \mathrm{MPa}$. Hence, the pressure used in this study (30 MPa) will not deform the carbon steel pipe plastically.

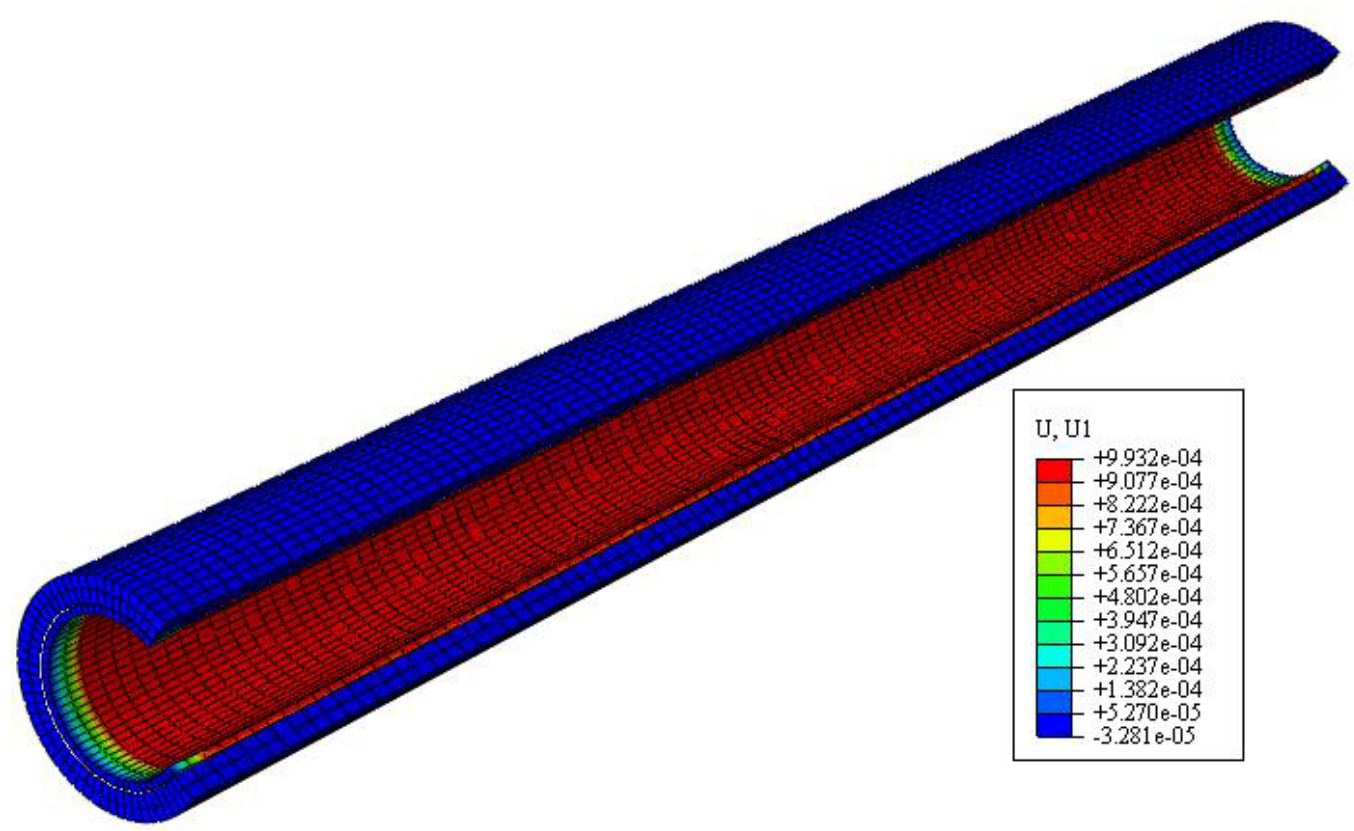

Figure 4: FEM model of double-walled CRA pipe of present study 


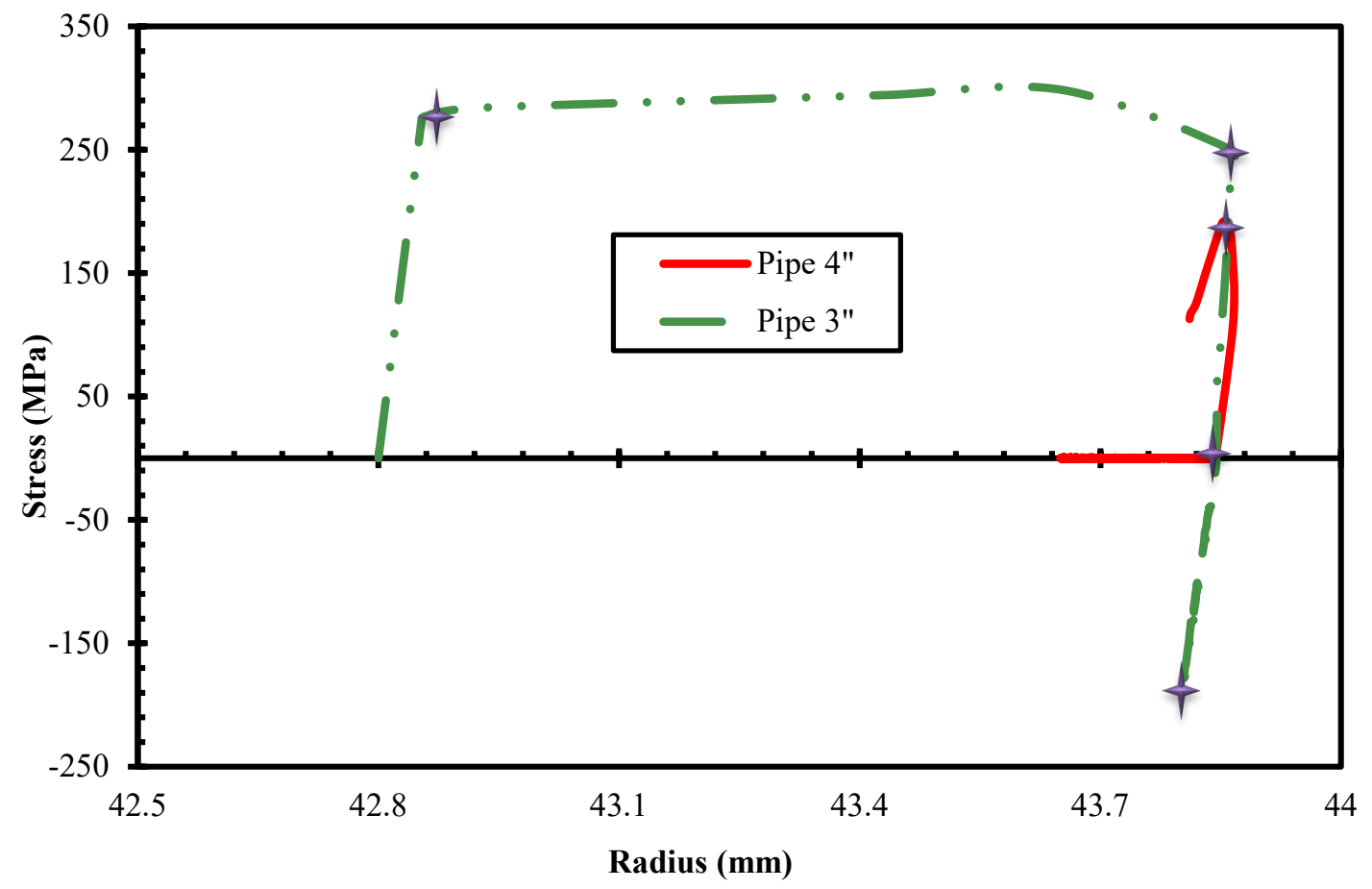

Figure 5: Stress/strain behaviour of inner and outer pipes (FEM simulation)

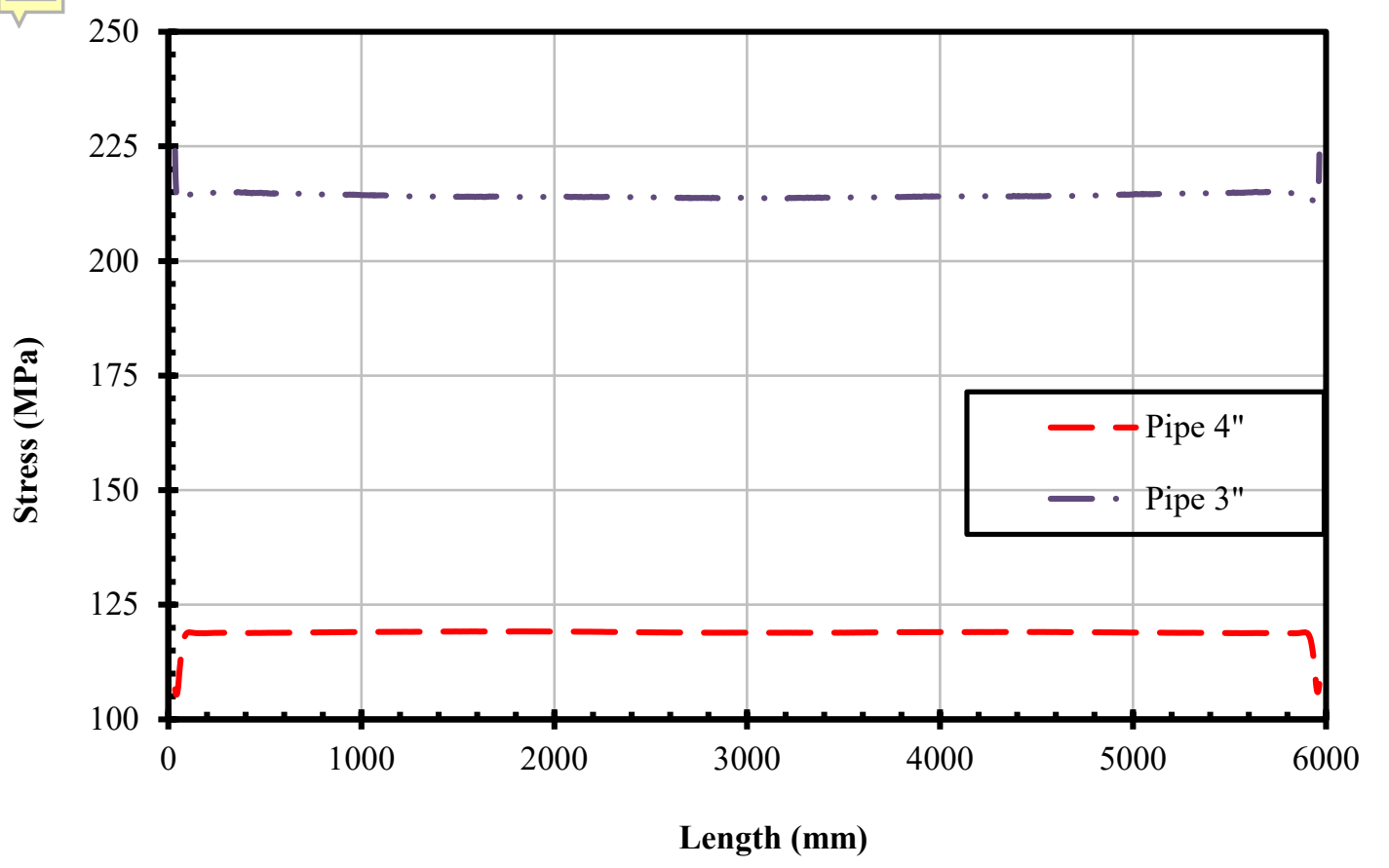

Figure 6: Hoop stress in outer and inner pipes for $50 \mathrm{MPa}$ internal pressure (FEM analysis)

Zheng et al. [8] presented a simplified theoretical model to predict the residual stress based on the internal hydraulic pressure, as follows. 


$$
P_{r c}=\frac{\left\{\frac{\left(P_{h}-\frac{2 t \sigma_{y i}}{r_{o i}+r_{i i}}\right)}{E_{o}\left(1-\frac{R_{i o}^{2}}{R_{o o}^{2}}\right)} \cdot\left[\left(1-v_{o}\right) \frac{R_{i o}^{2}}{R_{o o}^{2}}+\left(1+v_{o}\right)\right]-\sigma_{y i} / E_{i}\right\}}{\left\{\begin{array}{c}
\frac{1}{E_{i}} \cdot\left[\frac{R_{i o}^{2}+\left(R_{i o}-t \cdot r_{o i} / R_{i o}\right)^{2}}{R_{i o}^{2}-\left(R_{i o}-t \cdot r_{o i} / R_{i o}\right)^{2}}-v_{i}\right]+ \\
+\frac{1}{E_{o}} \cdot\left[\frac{R_{o O}^{2}+R_{i o}^{2}}{R_{o o}^{2}-R_{i o}^{2}}+v_{o}\right]
\end{array}\right\}} .
$$

By substituting the material properties of the current study in Eq. (7), the following relationship is obtained.

$$
\mathrm{P}_{\mathrm{rs}}=1.9 \mathrm{P}_{\mathrm{h}}-32.345
$$

Figure 7 illustrates a comparison of the results from the theoretical model by Zheng et al. [8] and the FEM results of the current study. It is clear from Fig. 7 that the agreement between the theoretical model and FEM results improves at higher internal hydraulic pressures. The probable reason for this discrepancy between the two models is that the effect of heating the outer pipe was not included in the theoretical model by Zheng et al. [8]. The heating effect is high compared with the total residual pressure at low hydraulic internal pressures, but its effect fades when increasing the internal pressure. As indicated in Fig. 7, the heating effect causes the observed higher residual stress at all production pressures.

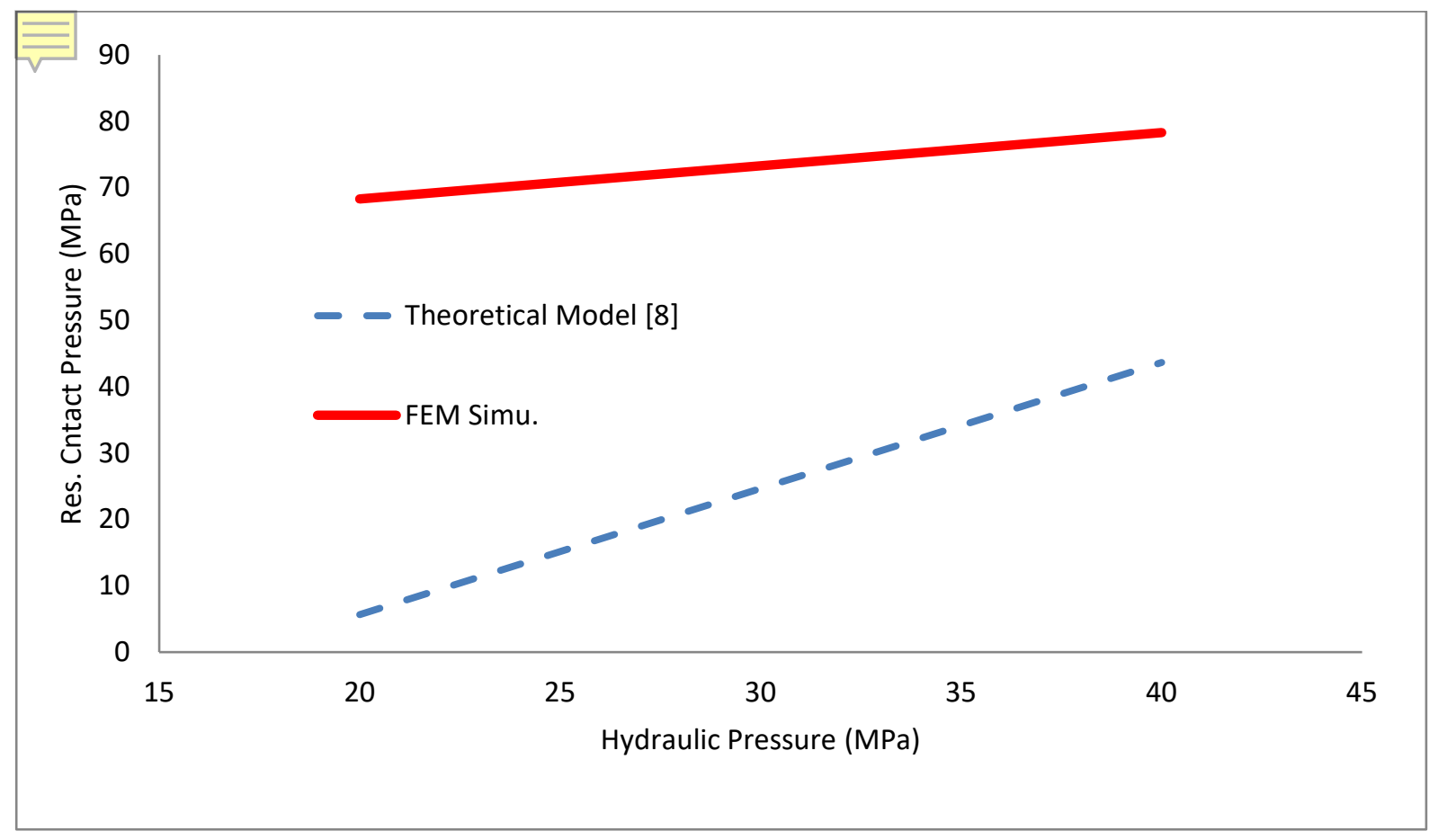

Figure 7: Comparison between FEM study and theoretical model of literature 


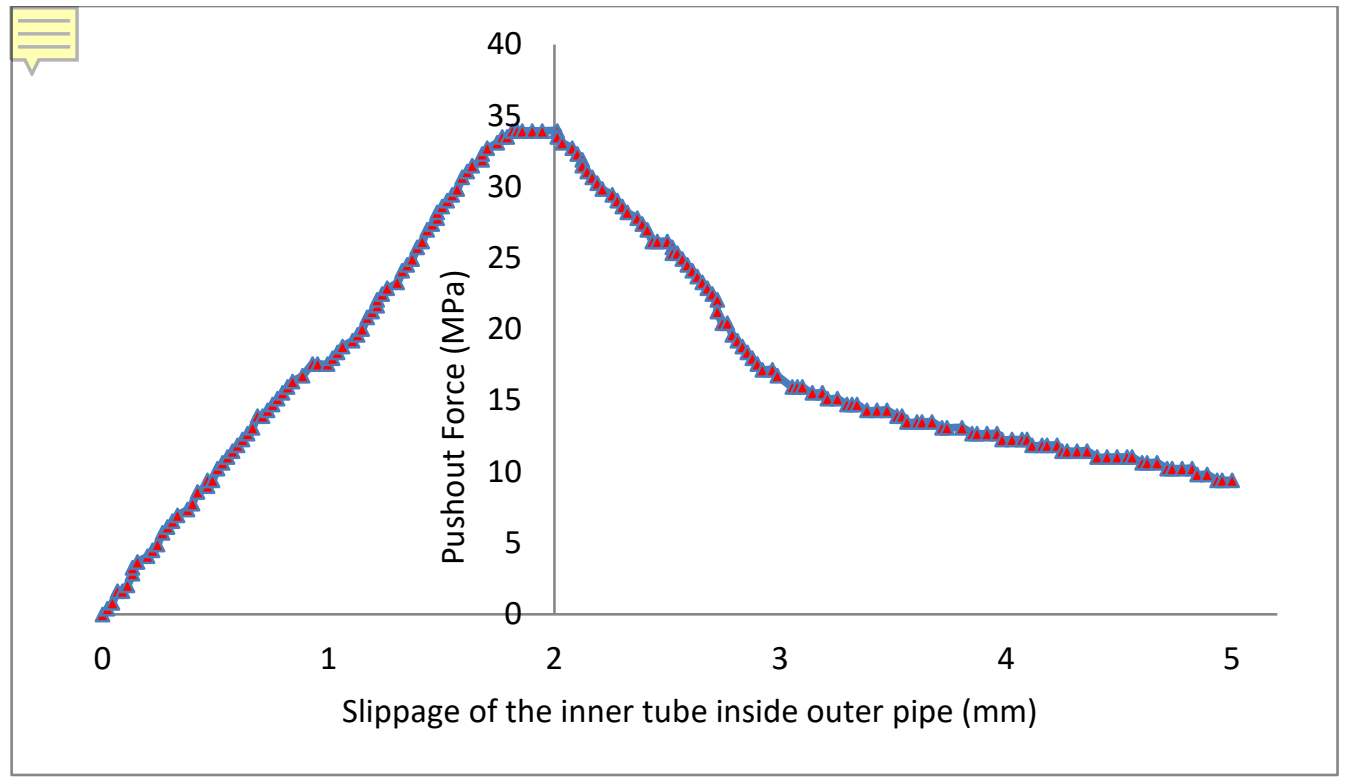

Figure 8: Required push-out force versus displacement curve

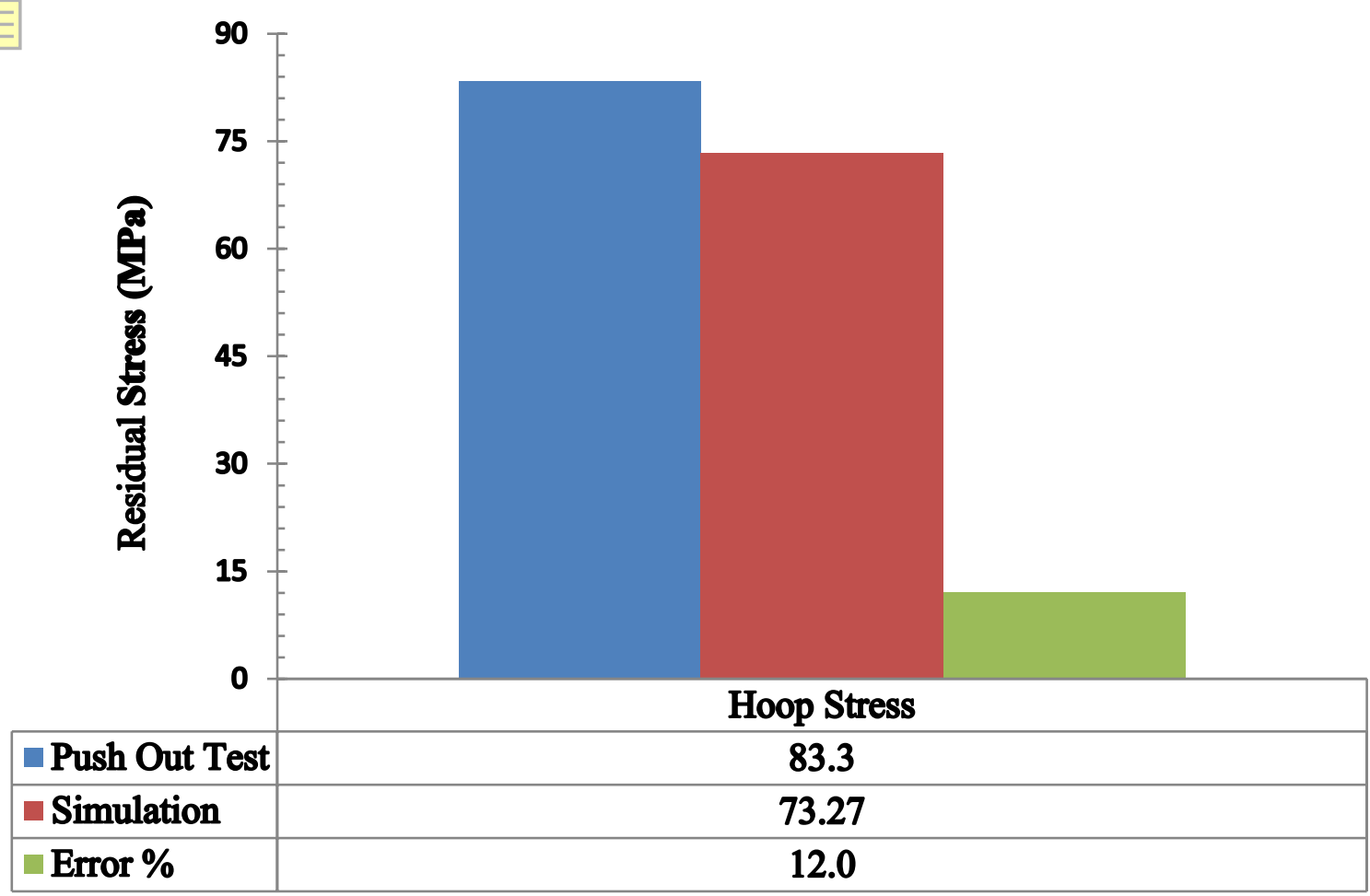

Figure 9: Experimental results for three gripping measurements

\subsection{Experiment}

As revealed from Fig. 3, several sections along the length of the inner pipe were dislodged from their carbon steel counterpart during the push-out test. Figure 8 illustrates the change in the force required for pushing the liner tube out of the outer pipe by increasing the dislodged length. The maximum push-out force in Fig. 8 was used to calculate the residual shear stress by means of Eq. (2), as illustrated in Fig. 9. In this case, the friction coefficient between the stainless steel tube and carbon steel pipe was assumed to be 0.46 [18]. It is clear from Fig. 9 
that the results of the FEM analysis correlate with the experimental measurements. According to the experimental results, the maximum required pressure for pushing out the inner tube is 33.94 MPa. There is no high axial load on a double-walled pipe in oil and gas and the majority of other common applications. Hence, this amount of gripping force is sufficient for resisting different loads under working conditions. Even the head pressures at the capped ends of the pipes will not pose any issue for these lined pipes.

Moreover, as illustrated in Fig. 10, a visual inspection of the prepared cross-sections from the produced lined pipes demonstrated that small laminations existed at one of the prepared cross-sections. It is evident that lamination-type defects are probable for this method of the manufacturing process. These defects may be locations of hydrogen concentrations and a source of hydrogen-induced defects in the working environment. Hence, it is strongly suggested to inspect the binding locations of the produced pipes by using an ultrasonic method.

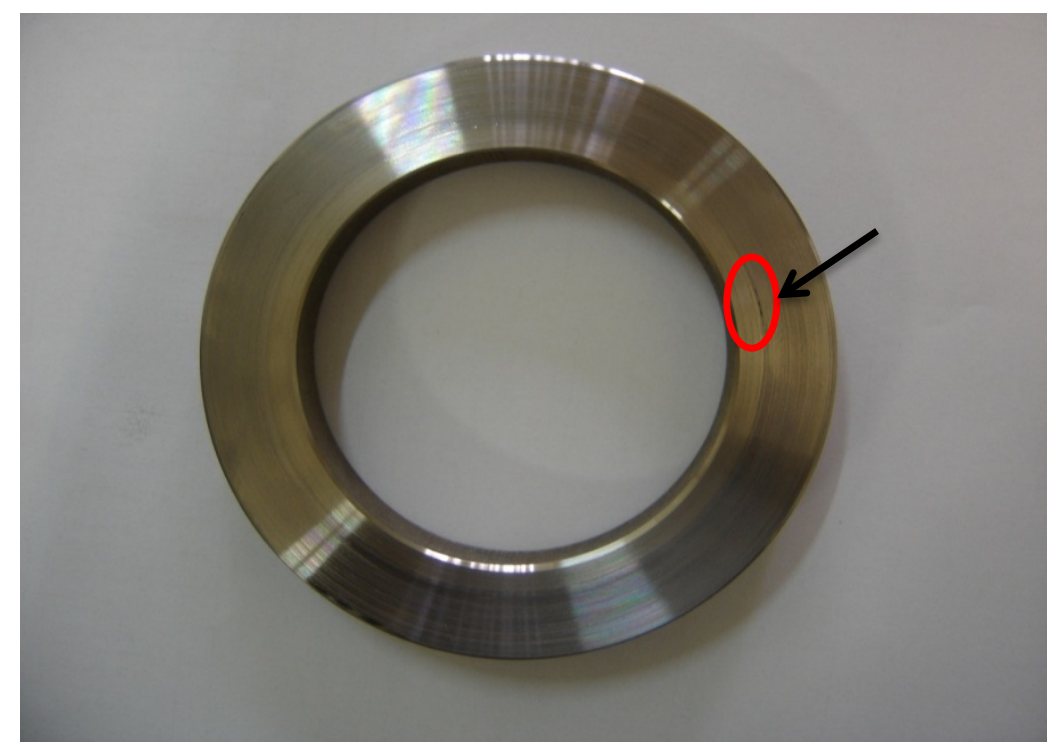

Figure 10: Cross-section of lined pipe for inspecting binding quality

\section{Conclusion}

In this study, a double-walled CRA pipe was produced using the THSF process, consisting of inner stainless and outer carbon steel. When conducting experimental THSF tests at $350^{\circ} \mathrm{C}$ and $30 \mathrm{MPa}$, the magnitude of the gripping force in the push-out tests between the inner and outer pipes was $33.94 \mathrm{MPa}$. This amount of binding force between pipes is sufficient for most applications. However, a visual inspection of the bonded regions in the prepared samples demonstrated that the possibility exists for small laminations. These laminations lead to hydrogen concentrations owing to the atomic process through wall diffusion. In addition to the experimental measurements, the stress/strain behaviours of the inner and outer pipes were evaluated using 3D FEM. A residual stress of $83.3 \mathrm{MPa}$ between the two pipes was identified in the results. The correlation error of the simulation and experimental results was $12 \%$. 


\section{References:}

[1] M. lannuzzi, A. Barnoush, R. Johnsen, Materials and Corrosion Trends in Offshore and Subsea Oil and Gas Production, 2017.

[2] H. Devold, 2013, Oil and gas production handbook: an introduction to oil and gas production, Lulu. com,

[3] E. F. o. C. (EFC), Corrosion Resistant Alloys for Oil and Gas Production: Guidance on General Requirements and Test Methods for H 2 S Service, EFC-17, Maney Publishing, 2002, pp. 96.

[4] A. P. I. (API), Corrosion Control Documents, 2017.

[5] K. Vedeld, H. A. Sollund, J. Hellesland, O. Fyrileiv, Effective axial forces in offshore lined and clad pipes, Engineering Structures, Vol. 66, pp. 66-80, 2014.

[6] A. P. Institute, API Specification 5LD CRA Clad or Lined Steel Pipe, 2009.

[7] F. Liu, J. Zheng, P. Xu, M. Xu, G. Zhu, Forming mechanism of double-layered tubes by internal hydraulic expansion, International Journal of Pressure Vessels and Piping, Vol. 81, No. 7, pp. 625-633, 2004.

[8] M. Zheng, H. Gao, H. Teng, J. Hu, Z. Tian, Y. Zhao, A simplified approach for the hydroforming process of bi-metallic composite pipe, Archives of Metallurgy and Materials, Vol. 62, No. 2, pp. 879-883, 2017.

[9] M. Mizumura, H. Mimura, H. Naoi, H. Higashiyama, Behavior of Mechanical-Bonding DoubleWall Pipe Under Various Loading Conditions, International Journal of Offshore and Polar Engineering, Vol. 4, No. 02, 1994.

[10] D. Vasilikis, S. A. Karamanos, Wrinkling of lined steel pipes under bending, in Proceeding of, American Society of Mechanical Engineers, pp. V04BT04A027-V04BT04A027.

[11] T. Zhao, Z. Hu, Numerical analysis of detaching and wrinkling of mechanically lined pipe during its spooling-on stage to the reel, Theoretical and Applied Mechanics Letters, Vol. 5, No. 5, pp. 205-209, 2015.

[12] E. Focke, Reeling of tight fit pipe (Ph. D. thesis), University of Delft, 2007.

[13] T. Guo, F. Ozturk, F. Jarrar, J. Y. Sheikh-Ahmad, Analysis of Contact Pressure of Mechanically Lined Corrosion Resistant Alloy Pipe by Hydraulic Expansion Process, Journal of Pressure Vessel Technology, Vol. 139, No. 2, pp. 021212, 2017.

[14] K. Vedeld, H. Osnes, O. Fyrileiv, Analytical expressions for stress distributions in lined pipes: Axial stress and contact pressure interaction, Marine Structures, Vol. 26, No. 1, pp. 1-26, 2012.

[15] Z. Dezhi, L. Yuanhua, Z. Dajiang, Y. Bin, Z. Hongjun, S. Taihe, Forming Force Calculation and Experimental Study on Hydro-Forming Process of Lined Steel Pipe, in Proceeding of, IEEE, pp. 246-250.

[16] E. Focke, A. Gresnigt, J. Meek, H. Nakasugi, The 2-Dimensional Modelling of the Manufacturing Process of Tight Fit Pipe (TFP), in Proceeding of, International Society of Offshore and Polar Engineers, pp.

[17] E. Focke, A. Gresnigt, J. Meek, H. Nakasugi, The influence of heating of the liner pipe during the manufacturing process of tight fit pipe, in Proceeding of, International Society of Offshore and Polar Engineers, pp.

[18] E. Focke, A. Gresnigt, J. Meek, H. Nakasugi, Experimental Research on Local Buckling Behaviour of Tight Fit Pipe, in Proceeding of, International Society of Offshore and Polar Engineers, pp. 